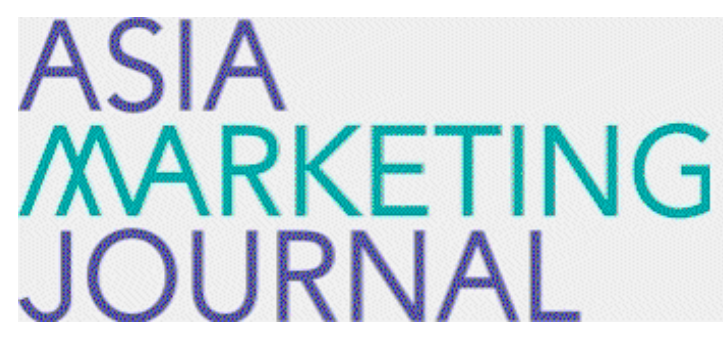

ASIA MARKETING JOURNAL

Volume 15 | Issue 2

Article 4

7-30-2013

\title{
Do good return policies work across cultures? Effect of lenient return policies on online shopper perceptions in Eastern culture
}

Su Jin Yang

Yun Jung Choi

Follow this and additional works at: https://amj.kma.re.kr/journal

Part of the Marketing Commons

\section{Recommended Citation}

Yang, Su Jin and Choi, Yun Jung (2013) "Do good return policies work across cultures? Effect of lenient return policies on online shopper perceptions in Eastern culture," Asia Marketing Journal: Vol. 15 : Iss. 2 , Article 4.

Available at: https://doi.org/10.53728/2765-6500.1519

This Article is brought to you for free and open access by Asia Marketing Journal. It has been accepted for inclusion in Asia Marketing Journal by an authorized editor of Asia Marketing Journal. 


\title{
Do good return policies work across cultures? Effect of lenient return policies on online shopper perceptions in Eastern culture
}

\author{
SuJin Yang* \\ Yun Jung Choi**
}

While good return policies are suggested as one of the critical services for e-commerce, ambivalence between the burden of the cost and shoppers' satisfaction may prevent e-tailers from increasing their level of leniency. Based on the S-O-R model, this study has attempted to develop a grounded theory to explain how lenient return policies shape online shoppers' perceptions and responses, with a focus on cultural influences in the relationship. In order to check the cultural effects of the lenient return policy, thirty two female and eleven male undergraduate students in South Korean shoppers, who are accustomed to strict return policies, participated in the semi-structured interview. A series of openended questions were designed to explore consumers reactions toward four different levels of the lenient return policy: from the strict type in South Korea to the lenient type in the U.S.

Using qualitative research methods, this research has defined three types of dimensions of lenient return policy: return possible period, complexity of progress, and other restrictions. While previous researchers did not pay much attention, the last dimension, other restrictions, is shown to be the most significant in influencing online shoppers' perceptions, especially in South Korea. Also, the impacts on online shoppers' perceptions from the three types of sub-dimensions of return policy were somewhat different. Whereas a longer return possible period was considered more favorable, a medium level of complexity and restrictions were considered more desirable. In summary, this result showed that shoppers in Eastern cultures, i.e. South Korean online shoppers, seem favorable to a medium level of lenient return policies, while allowing for taking precautions against possible fraudulent behaviors and setting other restrictions. Therefore, most of retailers in South Korea recommended that e-tailers who adopt the most lenient return policies raise the bar to guard ethical shoppers from fraudulent users.

Next, lenient return policies can enhance ease of use, usefulness, affect, and trust while relieving perceived risk, which is connected to intention to purchase, satisfaction, and loyalty. Interestingly, lenient return policies are more likely to change the behavioral responses of online shoppers, such as return and purchase, rather than change their attitudes or beliefs such as image, satisfaction, and loyalty. This tendency can be seen more clearly in the direct influences of return policy on responses.

\footnotetext{
* Ph. D. Samsung Economic Research Institute(sj0419.yang@samsung.com)

** Ph. D. Dept. of Design and Environmental Analysis, Cornell University(haiahl@snu.ac.kr), corresponding author
} 
The reaction to lenient return policy is mostly the intention to return or to purchase. This suggests that return policy serves the e-tailers as a powerful tool in increasing online shoppers' purchase intention at the moment of purchase.

Therefore, e-tailers who plan to expand their market to eastern countries, including South Korea, have to build a shield of restrictions around their lenient return policy, rather than immediately applying their original liberalized return policy. Also, e-tailers in South Korea need to review their strict and undifferentiated return policies to deal with the unsatisfied reactions of online shoppers toward their normal return policies. Although the present study was confined to the return policies currently being practiced by popular e-tailers, it would be worthwhile to develop effective return policies separately for each country, especially South Korea, keeping the culture of the relevant country in mind.

Key words: Return policy, S-O-R paradigm, Content analysis (or qualitative research)

\section{Introduction}

E-commerce continues to grow rapidly all over the world. In 2011, worldwide online retail sales reached about 400 billion dollars after taxes, which represent an increase of $13 \%$ over the last five years (AT Kearney, 2012). Since the online market is big, competition among $\mathrm{e}^{-}$ tailers is becoming severer. To ensure success, e-tailers need to differentiate themselves from others through innovative strategies that can deliver a high level of satisfaction to customers. Return policy is one differentiating strategy that can increase customers' satisfaction and buying intention in online shopping malls (Bonifield. Cole, \& Schultz, 2010). In online shopping, consumers have to pay for a product without experiencing it and by simply relying on the credibility and reputation of the e-tailer.
This inborn limitation of online shopping increases the chances of shoppers wanting to return a purchased product when it turns out to be different from what they expected. Because of this limitation, online shoppers count on a return policy, including an in-store return option, as the second attractive incentive for online shopping, the first one being free shipping (Compete, 2011).

As shoppers tend to be attracted to a lenient return policy (Davis, 2001), many e-tailers in Western countries have liberalized their return policies to improve customer satisfaction and thus increase their online sales. For example, Zappos.com successfully increased its sales by $1300 \%$ over the last 10 years by providing its customers with both-way free shipping, 1 full year for return, and 24 hour call centers (Hsieh, 2010). Online shoppers in the U.S. and Europe are similarly enjoying more lenient return poli- 
cies that go against government mandated laws (Harris, 2010: Mostard \& Teunter, 2006). On the other hand, consumers in South Korea, where over $70 \%$ of the population participates in online shopping and where $\mathrm{B} 2 \mathrm{C}$ e-commerce sales in 2011 amounted to 26.7 billion dollars, experience inferior return services (The Korea Chamber of Commerce \& Industry, 2011). In the absence of any government mandated consumer protection laws, e-tailers in South Korea have raised the bar on return policies, by for example, insisting on 7 day returns, even when the delivered products arrive damaged due to the fault of the company. Recently, as global e-tailers have expanded their business to newly developing countries, especially in Asia, their lenient return services have started attracting consumers in South Korea as well. As a consequence, the domestic players have been forced to improve their return policies (Yoon, 2007). But global e-tailers hesitate to apply their original lenient return policies to developing countries in the same way that they offered them to the Western market because of concerns about fraudulent use.

Despite much attention being given to the ambivalence in lenient return policies, no comprehensive research has been carried out, to the authors' knowledge, on the responses to return policies among consumers of different cultures (Wood, 2001: Babakus, Cornwell, Mitchell, \& Schlegelmilch, 2004). This is mainly because consumers' fraudulent intention is usually biased when it is self-surveyed and is therefore hard to capture. Therefore, in-depth interviews were conducted with South Korean consumers to assess the effect of lenient return policies on consumers' perceptions and behavioral intentions. A qualitative approach was employed due to the sensitive nature of the topic. This study will provide a better understanding of the complicated features of generous return policies and identify several variables related to the effect of return policy on consumers, such as personal traits or cultural aspects. This study will also provide domestic as well as global $\mathrm{e}$-tailers a new perspective on return policies as well as useful directions for future strategies.

\section{Literature Review}

\subsection{Effects of lenient return policies on consumer behavior}

Traditionally, level of leniency has been considered an important strategy for retailers, along with price and product assortment (Davis, Hagerty, \& Hagerty, 1998: Ketzenberg \& Zuidwijk, 2009). Moreover, as remote purchases involve surges in online shopping, lenient return policies have become more important than ever (Wood, 2001). Inherently, online shoppers have to take the risk of paying for products which they can only experience physically after the 
delivery of the actual product and not before (Lee \& Kim, 2000). Because of this inherent risk of e-tailing, it is natural for consumers to return products more frequently, which leads to increased costs for e-tailers. To eliminate online shoppers' risk and improve sales, lenient return policies have become critical (Davis, 2001). But the costs related to the return process, such as shipping, repackaging, and operating managing centers, will place huge pressure on e-tailers.

Many researchers have pointed out the tradeoff that e-tailers are likely to face in executing a lenient return policy. From a positive perspective, lenient return policy is a significant pre-purchase signal which can reduce online shoppers' perceived risk, increase sales, and enhance shoppers' trust or satisfaction toward $\mathrm{e}^{-}$ tailers (King, Dennis, \& Wright, 2008). Wood (2001) showed that return policy leniency of off-site retailers decreases the deliberation time involved in consumer purchase decision and increases the pre-receipt expectation of product quality. Most consumers rely on return policies as a signal of e-tailers' quality in the online shopping context because these e-tailers stand behind their products and services (Bonifield et al., 2010).

On the other hand, several researchers have noticed the dark side of generous return policies, which induce the consumers to make opportunistic and unethical use of retailers' offers (Watchter, Vitell, Shelton, \& Kyungae, 2012).
If the return policy is more lenient, it is more likely to increase fraudulent behavior on the part of consumers in returning goods and services (Davis, et al., 1998: King et al., 2008). According to King and his colleagues (2007), $50 \%$ of returns in clothing were fraudulent in the U.S. The abuse of lenient return policies by the consumers may add to companies' costs and finally end up eroding their profits. Also, if other innocent consumers happen to buy the repackaged products, they can feel dissatisfied and have a sense of victimization that can ruin companies' reputation (Harris, 2008).

To mitigate the apprehension about adopting a lenient return policy, some researchers have attempted to find out what should be the right amount of leniency. However, most of these researchers have focused their attention on manufacturers' or retailers' perspectives on profits rather than consumers' perceptions and behavioral changes (Wood, 2001). Thus, these researchers concluded that the level of leniency in return policies has to be determined by considering the product type, such as perishable goods (Lau \& Lau, 1999), build-to-order (Mukhopadhyay \& Setoputro, 2004), or products with salvage value after return (Davis et al, 1998) because the costs involved in having a lenient return policy are greater than the positive effects expected, such as increasing sales. Also, researchers have tended to treat return policy as a one-dimensional issue, even though lenient return policy can be determined 
by various elements such as return possible period, complexity of process, and refund type (Davis, et al., 1998: Bonifield et al., 2010). However, admitting a return policy is very critical in an e-commerce context, so which element of the return policy determines its leniency and how the level of leniency influences consumers' perceptions and behavior need to be explored. For this, one needs to go into more detail on the return policy. For example, Bonifield et al. (2010) coded the return policy leniency of 141 e-tailers using the REM index (availability of Refunds, Exchanges, and Merchandise credits) as well as the Restriction index. The Restriction index includes the return label, time limits, return shipping, restocking fees, original shipping and handling, preauthorization, and customer contact information. Wood (2001) pointed out that the conditions for a lenient return policy include time limit, restriction, refund method, and return of sale items. For a broader perspective on previous studies of the different characteristics and effects of lenient return policies, this study focused on the details of the elements of the leniency characteristics of a return policy, which can actually influence consumers' perceptions and choice process. Qualitative methods were adopted to obtain both positive and negative perspectives on the relationships existing among the different elements of the leniency of the return policy and consumers' inner state and responses toward the e-retailers.

\subsection{Comparison of return policies in South Korea and the United States}

The other aspect that the current study is looking at is the impact of culture on online shoppers' responses toward a lenient return policy. As the online marketplace is becoming wider and more diverse, e-tailers must show an interest in understanding the differences in online consumer behaviors across the world, and they must also be ready to face globalization challenges. For global retailers in developed countries that are looking for an opportunity to rise to the next level of growth, having a global e-commerce strategy is considered a good channel to use in appealing to developing countries such as China and Malaysia (AT Kearney, 2012). However, one topic that has received little attention from researchers to date is a comparison of consumers' behaviors toward lenient return policies across different cultures. Therefore, this study has tried to capture the effect of culture on online shoppers perceptions of lenient return policies, focusing particularly on how South Koreans respond to the return policies in South Korea as well as in the United States.

First, the Internet business is well developed in both countries with highly advanced technology. In South Korea, where Internet penetration was up to $80 \%$ in 2007 , Internet users spent about $2 \%$ of their country's GDP on online shopping in 2010 (Statistics Korea, 2011). Thus, online 
shopping in South Korea is expected to take a large share of the retail industry, second to that of offline supercenters such as Emart and Homeplus, contributing thereby to the biggest growth rate of about $16.9 \%$ compare to the other retailing channels including online shopping (Lotte Distribution Strategy Research Institute, 2011).

Next, the levels of leniency in return policy are totally different between South Korea and the U.S.. Evidently, the U.S. and U.K. are well-known for their generous return policies with almost unconditional guarantees (King et al., 2008). Even so, in South Korea, the return policy remained rather underutilized considering the size of the online market (Yoon, 2007). Therefore, researchers identified the deficiencies in retailers' return policies in South Korea and recommended their reform to protect consumers' interests (Yoon, 2007). At the same time, there has also been concern about the fraudulent use of return policies by consumers in South Korea. These return policies have been liberalized to the level of those in Western countries. Because the level of education and sense of vigilance are known to be low among the consumers in newly developing countries, including South Korea, unethical behavior is expected to be more common and frequent in that country. However, there is no evidence to show that the consumers in developing countries practice fraud because they have no knowledge of unethical and questionable behaviors (Babakus, et al., 2004). Therefore, the authors of this research propose to analyze not only the effects of lenient return policies, but also how culture plays a role in causing these effects by studying the way South Korean consumers perceive and behave in the face of the lenient return policies in the U.S..

\section{$2.3 \mathrm{~S}-0-\mathrm{R}$ model hypothesizing research questions}

The Stimulus-Organism-Response (S-O-R) model was utilized in building research questions on the influence of generous return policies on online shoppers' behavioral issues, taking into account their cultural background. This theory states that stimuli in the environment may affect individuals' cognitive and emotional states, which finally determine behavior responses such as "approach" or "avoidance" (Mehrabian \& Russell, 1974). This classic model has been used empirically in various formats ranging from offline (e.g., Baker, 1987: Bitner, 1992) to online stores Eroglu, Machleit, \& Davis, 2003: Mummalaneni, 2005: Sautter, et al., 2004: Wang, Baker, Wagner, \& Wakefield, 2007). As factors trigger a change in consumers' internal state, the type of stimulus that describes the atmospherics of the physical store varies according to the shopping context.

When consumers face the stimuli from $e^{-t a i-}$ lers, their organisms and responses are shaped. In introducing the classic S-O-R paradigm to 
the physical retail environment, Donovan and Rossiter (1982) split the dimension of organism into three emotional states: Pleasure, Arousal, and Dominance (PAD). According to them, behavioral response is manipulated in only two ways, namely "avoidance" and "approach" outcomes. However, recently, the dimension of organism has been extended to include the general concept of the attitude that consumers may develop toward the atmosphere of online stores in cognitive as well as emotional ways (Eroglu, Machleit, \& Davis, 2001: Eroglu et al., 2003: Fiore \& Kim, 2007). As has already been mentioned, the focus of this research is on unethical behaviors toward return policy. Several researchers consider that consumers with a fraudulent attitude are likely to exploit the leniency of return policies (Harris, 2008; King et al., 2008).

As such, the perspective of responses has been broadened to add behavioral intention, including value (e.g., Fiore \& Kim, 2007), satisfaction (e.g., Eroglu et al, 2003), and patronage intention (e.g., Wang, et al, 2007) to $\mathrm{ac}^{-}$ tual behavior. Given the purpose of this study, the S-O-R model seems appropriate to capture the relationships among the elements of the authors' interest in such features as return policies. As such, the level of leniency in terms of return policy can be determined as "Stimulus," online shoppers' perceptions shaped according to the features as "Organism," and the final behaviors such as intended loyalty or fraudu- lent return as "Responses."

When it comes to cultural effect of the main model, past researchers utilizing the S-O-R model have considered that consumer characteristics can moderate the relationship between stimulus and organism such as gender (Eroglu, et al., 2003), familiarity toward the website (Chen \& Dibb, 2010), and culture (Davis, Wang, \& Lindridge, 2008). Generally, cultural elements are explained by individualism (or collectivism), masculinity (or femininity), uncertainty avoidance, power distance, and long-term orientation, as suggested by Hofstede (2001). In particular, individualism (or collectivism) and uncertainty avoidance are considered key descriptive factors that distinguish Eastern culture from Western culture (Frost, Goode, \& Hart, 2010). Specifically, individualism is defined as the level of independence from social interaction and collectivism as interdependence between individuals and groups. Also, people from countries with strong uncertainty avoidance culture have higher needs for norm, structure, and strong faith in organizations such as companies or governments, as compared to the needs of people from countries with weak uncertainty avoidance culture (Hofstede, 2001). According to Hofstede (2001), South Korea has strong uncertainty avoidance and collectivism, while the U.S. has weak uncertainty avoidance and individualism.

In terms of the S-O-R model, the research topic leads broadly to three questions: 1) Given 
the stimulus of a lenient return policy, what kind of organism and responses are South Korean shoppers likely to show? 2) How are the stimuli related to organism and responses? 3) How do the cultural elements of collectivism and high level of uncertainty avoidance moderate the influence of the stimuli on organism and responses?

\section{Methods}

Since the current research assumes that some consumers will exhibit fraudulent behaviors and utilize lenient return policies in unethical ways, consumers may disguise the truth of their feelings and intentions when being asked to participate in quantitative research methods, including surveys. A series of recent research dealing with consumers' unethical issues tended to apply qualitative research methods utilizing a small size of a purposive sample so as to avoid participants' social desirability masking (Shaw \& Newholm, 2002: Cherrier, 2006). Following this line, the authors adopted a qualitative method involving in-depth interviews with online shoppers to investigate how they responded to a lenient return policy. Regarding research methods, Clavin and Lewis (2005) explained that interviews and focus groups are more reliable for eliciting richer insights into sensitive phenomena such as ethical issues. Also, qualitative methods provide a depth of rich and flexible data with which researchers can analyze and interpret consumers' motivations, concerns, and thoughts (Clavin \& Lewis, 2005: Barnett et al., 2008). Additionally, because not much research has been carried out on studying the effect of specific lenient return policies along with cultural views, phenomenological depth interviews were considered adequate for this kind of research with a discovery oriented purpose (Thompson, Zanna, \& Griffin, 1995). Specifically, the methodological approach of the grounded theory was utilized for this study to investigate, in terms of the S-O-R model, the theoretical understanding of the responses of the South Korean online shoppers in the United States toward a lenient return policy.

\subsection{Stimulus}

In processing the in-depth interviews with online shoppers, the first step was to develop the stimulus for lenient return policies, considering the return policies of e-tailers in both South Korea and the U.S.. To capture the e-tail industry's overall competing situation, three types of e-tailers were selected from both South Korea and the U.S.. The first type of e-tailer was Auction Korea from South Korea and Zappos from the U.S., both of which are well known for providing the most generous return policies. Auction Korea has recently 
tried to differentiate itself with its special return services, including a call center and free return coupons. Zappos has been very popular for supporting its customers with almost unlimited return benefits. The second type of e-tailer is Gmarket from South Korea and amazon.com from the U.S., both of which are ranked as the highest sale-yielding companies. The third type of e-tailer is emartmall from South Korea and Walmart from the U.S., both of which operate nationwide as the number one offline retail store, besides having an online channel.

After selecting the six e-tailers, the elements that make their return policies lenient were extracted. While the return policies of South Korea are relatively long and complicated to understand at a glance, those of US e-tailers are short and comprehensive. To extract the elements of the lenient policies, 45 undergraduate students from Seoul, South Korea were asked to identify the policies that make an e-tailer either lenient or strict in terms of return by reviewing two return policies, one from South Korea and the other from the U.S.. College students from South Korea seem to be a good sample of online shoppers because they have been known as the main buying group for visiting online shopping malls, over 9 times a month (The Korea Chamber of Commerce \& Industry, 2012). Also, all the participants were recognized as good, experienced online shoppers, besides being able to read Korean and English.
In total, 90 evaluations, at the rate of 15 evaluations for each e-tailer, were gathered. Only those policies that were designated as being generous by over 90 percent of the students were retained for this study. The details on the lenient policies so selected are shown in Table 1. Then, the lenient policies selected were categorized into four sections by two researchers, such as the return-possible period, complexity of the process, and other restrictions. Davis and colleagues (1998) recognized that level of leniency is likely to comprise multiple dimensions, such as return possible period and complexity of process. For this study, the other restrictions added to the main return policy were considered separately to make the comparison between South Korea and the U.S. more distinct. To clarify, "other restrictions" in South Korea, which make return more difficult, seem to be "other support" in the U.S., which makes return easier in that country.

For further analysis, the selected return policies of the four sections were ranked according to their leniency. Besides Auction with a special call center, there is very little difference between the three e-tailers in South Korea: therefore, all of them were ranked at the same level as RP1, CP1, and OR1 (shown in Table 1). This tendency, which merely follows mandated governmental law for consumer protection. was pointed out by earlier workers who analyzed the return policies in South Korea (Yoon, 2007). Only Auction's return policies 
$\langle$ Table 1〉 Summary of lenient return policies of e-tailers

\begin{tabular}{|c|c|c|c|}
\hline \multirow[b]{2}{*}{ e-tailer } & \multicolumn{3}{|c|}{ Leniency of return policies (Rank) } \\
\hline & $\begin{array}{l}\text { Return } \\
\text { Period }\end{array}$ & Complexity of Process & Other Restrictions \\
\hline Gmarket & $\begin{array}{l}7 \text { days } \\
\text { - In case of } \\
\text { seller's } \\
\text { fault, } 30 \\
\text { days } \\
\text { (RP1) }\end{array}$ & $\begin{array}{l}\text { - Customer pays for two-way returns } \\
\text { - Available only for designated delivery } \\
\text { company } \\
\text { - Return process starts after return cost } \\
\text { is paid in advance } \\
\text { - Return processes, including registration, } \\
\text { return cost, notice of pick-up, are all } \\
\text { customer' responsibilities } \\
\text { (CP1) }\end{array}$ & $\begin{array}{l}\text { - No free returns are allowed for any } \\
\text { reason (e.g., different quality from } \\
\text { what customer expected, etc.) other } \\
\text { than seller's fault. } \\
\text { - Free return service coupons according } \\
\text { to customer grade } \\
\text { - Too many conditions for actual usage } \\
\text { of free coupon (e.g., price, product } \\
\text { type, vender type) } \\
\text { (OR1) }\end{array}$ \\
\hline Emart & $\begin{array}{l}7 \text { days } \\
\text { (RP1) }\end{array}$ & $\begin{array}{l}\text { - Possible to return to offline offices, } \\
\text { excepting the six offices in special } \\
\text { areas } \\
\text { (CP1) }\end{array}$ & $\begin{array}{l}\text { - Return services are not offered for } \\
\text { allied companies' products } \\
\text { - Fresh products can be returned only to } \\
\text { offline offices in } 1-2 \text { days } \\
\text { (OR1) }\end{array}$ \\
\hline Auction & $\begin{array}{l}7 \text { days } \\
\text { (RP1) }\end{array}$ & $\begin{array}{l}\text { - Only through call centers (working } \\
9 \text { am } ~ 6 \mathrm{pm} \text { ); return processes can be } \\
\text { handled without customer's } \\
\text { responsibility } \\
\text { - Otherwise, the return processes are as } \\
\text { complex as those of other e-tailers. } \\
\text { (CP2) }\end{array}$ & $\begin{array}{l}\text { - One free return coupon per month } \\
\text { - Too many conditions in usage of free } \\
\text { coupons (e.g.. price, product type, } \\
\text { vender type) } \\
\text { (OR1) }\end{array}$ \\
\hline amazon & $\begin{array}{l}30 \text { days } \\
\text { (RP2) }\end{array}$ & $\begin{array}{l}\text { - Available from all types of delivery } \\
\text { companies } \\
\text { - The invoice can be printed and the } \\
\text { delivery process checked through the } \\
\text { website. } \\
\text { - Costs related to refund apply } \\
\text { automatically. } \\
\text { (CP3) }\end{array}$ & $\begin{array}{l}\text { - Extension of return periods for specific } \\
\text { products (e.g.. baby clothing) } \\
\text { - Able to return even after } 30 \text { days with } \\
\text { subtraction of price } \\
\text { (OR2) }\end{array}$ \\
\hline Walmart & $\begin{array}{l}90 \text { days } \\
\text { (RP3) }\end{array}$ & $\begin{array}{l}\text { - Round the clock free return to offline } \\
\text { offices near home } \\
\text { (CP3) }\end{array}$ & $\begin{array}{l}\text { - Shorter possible return period for } \\
\text { electronic products } \\
\text { - Must keep manufacturer's packaging } \\
\text { - Can return without receipt when } \\
\text { returning to offline offices } \\
\text { (OR3) }\end{array}$ \\
\hline Zappos & $\begin{array}{l}365 \text { days } \\
\text { (RP4) }\end{array}$ & $\begin{array}{l}\text { - Round the clock return through special } \\
\text { call centers: all returns can be } \\
\text { handled without any effort } \\
\text { - Invoice can be printed and delivery } \\
\text { process checked through website or } \\
\text { call centers } \\
\text { (CP4) }\end{array}$ & $\begin{array}{l}\text { - No restrictions } \\
\text { - Free for all returns } \\
\text { (OR4) }\end{array}$ \\
\hline
\end{tabular}

${ }^{* *}$ RP: Return possible period, CP: Complexity of process, OR: Other Restrictions 
were ranked as $\mathrm{CP} 2$ and $\mathrm{CCl}$ due to the special call center. As regards the three e-tailers in the U.S., whenever one special lenient return policy was added to a certain e-tailer, its ranks in the section improved.

\subsection{Semi-structured interviews}

Thirty two female and 11 male undergraduate students participated in the semi-structured interview. A series of open-ended questions were designed to explore consumers' reactions toward two types of returns: the strict type from South Korea and the lenient type from the U.S. The return policies, summarized in Table 1, were randomly selected and presented without brand names so as to save the participants from possible loyalty towards or bias from previously shaped attitude to a particular brand. The participants were asked to state freely how they felt about the two given return policies. When they failed to specify the stimulus that made them feel the way they did, the interviewer interrupted by asking them to choose a certain return policy based on their perceptions and responses. Such interruptions allowed the researchers to understand the relationships among the return policies (stimulus), perceptions (organism), and choices (responses). theory (Charmaz, 2006: Strauss \& Corbin, 1998), the axial grounded theory coding process was utilized to decompose the interview transcripts into the stimulus, as well as induced organism and responses by the stimulus. Even though several stimuli can lead to the same organism and responses, the relationships were deconstructed into several organisms and responses depending on the stimulus. The organisms and responses were then reassembled into a consistent theory to explain the story of the interviewees from a holistic perspective. Data interpretation gave rise to themes, which were grouped based on their relationships within the S-O-R framework. Each construct of Organism and Response stages was independently analyzed by two researchers using a predetermined category system derived from the literature dealing with online shoppers' perceptions and behavioral responses. If the responses did not fit into predetermined categories, the researchers added a new category based on the discussion. During the coding process, the frequency of each construct mentioned by respondents was calculated (shown in Table 2). In the data interpretation that follows, constructs below frequency five, i.e., perceived quality in organism and deliberation time and shopping time in response, were excluded.

\subsection{Analysis and data interpretation}

After a critical analysis of the grounded 


\section{Results}

During the first stage of the coding process, the researchers classified respondents' internal states into two categories: cognitive and affective states. Then, cognitive states were subdivided into ease of use, usefulness, perceived risk, and trust. Admitting that return policy forms one of the critical elements of e-commerce, sub-categories of cognitive states were derived from the Technology Acceptance Model (TAM), which enables information system users to adopt and utilize the technology (Davis, 1989). The main constructs of TAM are "ease of use" and "usefulness," which accelerate users' acceptance of technology. An in-depth study of TAM shows that TAM can be further improved with the help of other constructs: perceived risk and trust (Kim, Ferrin, Rao, 2003: Pavlou \& Fygenson, 2006: Kim \& Prabhakar. 2000). Kim et al. (2003) consider perceived risk as an inherent quality of e-commerce because remote purchase and payment have to be executed with no physical contact between either the seller or the product. As such, trust becomes a necessity for online service providers to dispel the inherent risk. In addition, the "responses" category was coded as actual behavior, such as "time and money spent,". "product purchase," or "return,", and as "behavioral intention" such as "loyalty for retailers" or "satisfaction." Based on TAM, the cognitive organisms can possibly be related to behavioral intentions and/or actual behaviors. In terms of behavioral issues besides return and purchases, unplanned purchases appear to be one of the negative effects of a lenient return policy.

\subsection{Organisms and Responses driven by lenient return policies}

To understand what kinds of organisms and responses are strongly driven by the stimuli, the authors counted the frequency at which the coded organisms and responses were mentioned in the interviews. As shown in Table 2, when dealing with lenient policies, South Korean shoppers are most likely to perceive usefulness of return. They answered that lenient policies not only relieved them from the perceived risk of online shopping, but also made the return of products easier. Moreover, they had a strong tendency to develop affection toward e-tailers. They further asserted that they most frequently preferred to purchase and return at online shopping malls that had lenient return policies. The interviewees specifically mentioned that about $30 \%$ of their purchases were unplanned purchases, which were thus likely to reach the stage of return. Additionally, they responded by saying that image, satisfaction, and even loyalty to e-tailers were likely to improve when the e-tailers offered a lenient return policy. 
〈Table 2〉 Frequency of coded constructs in the S-0-R model for lenient return policies

\begin{tabular}{|lc|lc|lc|}
\hline \multicolumn{2}{|c|}{ Stimulus } & \multicolumn{2}{c|}{ Organism } & \multicolumn{2}{c|}{ Response } \\
\hline Return possible period & 57 & Affection & 60 & Short-term & 64 \\
Complexity of process & 86 & Cognition & & Purchase & 49 \\
Other restrictions & 198 & Usefulness & 69 & Return & \\
& & Perceived risk & 60 & Long-term & 25 \\
& & Ease of use & 42 & Image & 16 \\
& Trust & 13 & Satisfaction & 13 \\
\hline
\end{tabular}

\subsection{Influence of the stimuli on organism}

By linking the relationship between the stimuli and organisms, this study attempted to develop, following axial grounded theory, the theoretical influences of lenient return policies on online shoppers' perceptions and attitudes toward e-tailers (Charmaz, 2006: Strauss \& Corbin, 1998). Strength of relationship was assessed by the percentage of frequency that a certain organism was mentioned over the entire frequency of different types of organisms $(n=280)$. As shown in Table 3, for the three dimensions of return policy, namely "return possible period," "complexity of process," and "other restrictions," the frequency at which a certain type of $\mathrm{di}^{-}$ mension was mentioned as influencing interviewees' perceptions was counted.

Return possible period: A long return possible period beyond a month (RP2 RP4), which is offered only in the U.S., led to more positive effects $(n=30,10.7 \%)$ than negative ones $(\mathrm{n}=11,3.9 \%)$. As shown in Table 3, among all the identified $280 \mathrm{~S}-\mathrm{O}$ relationships, the most frequently cited internal state about return possible period was the decrease in perceived risk by $4.6 \%(R P 2=4, R P 3=1, R P 4=8)$. Conversely, the shortest return possible period (RP1) led to an increase in online shoppers' perceived risk $(n=2,0.7 \%)$, and also in loss of usefulness $(n=5,1.4 \%$ ), although this commonly applied to e-tailers in South Korea. Overall, the longer the return period offered by the e-tailer, the more were the positive organisms perceived by online shoppers along with the decrease in perceived risk and increase in affect and trust $(\mathrm{n}=31,8.1 \%)$. However, return possible period is unlikely to be critical in determining the usefulness of a return policy. While the participants held a negative view about RP1 and RP2, they held a neutral view about RP3 and RP4. Thus, a return possible period is more likely to be negative in online shoppers' perceived usefulness.

Interestingly, a few respondents commented that the increase in the return possible period up to a year might lead to negative internal states, such as increase of perceived risk and 
〈Table 3〉 Relationship between stimulus and organism

\begin{tabular}{|c|c|c|c|c|c|c|c|c|c|c|c|c|}
\hline & \multicolumn{2}{|c|}{ Affect } & \multicolumn{2}{|c|}{ P. risk } & \multicolumn{2}{|c|}{ Ease of use } & \multicolumn{2}{|c|}{ Usefulness } & \multicolumn{2}{|c|}{ Trust } & \multicolumn{2}{|c|}{ Sum } \\
\hline & + & - & + & - & + & - & + & - & + & - & P & $\mathrm{N}$ \\
\hline RP1 & 1 & & 2 & & & & & 4 & & & $1(0.4)$ & $6(2.1)$ \\
\hline RP2 & 2 & 1 & & 4 & & & 1 & 3 & 3 & & $10(3.6)$ & $4(1.4)$ \\
\hline RP3 & 1 & 1 & & 1 & 2 & & 1 & 1 & & & $5(1.8)$ & $2(0.7)$ \\
\hline RP4 & 2 & & 4 & 8 & 1 & & 1 & 1 & 3 & & $15(5.4)$ & $5(1.8)$ \\
\hline Sum & $6(2.1)$ & $2(0.7)$ & $6(2.1)$ & $13(4.6)$ & $3(1.1)$ & $0(0.0)$ & $3(1.1)$ & $9(3.2)$ & $6(2.1)$ & $0(0.0)$ & $31(8.1)$ & $17(6.1)$ \\
\hline $\mathrm{CP} 1$ & & & 1 & & & & & 6 & & & $0(0.0)$ & $7(2,5)$ \\
\hline $\mathrm{CP} 2$ & & & 1 & 2 & 5 & & & 3 & 2 & & $9(3.2)$ & $4(1.4)$ \\
\hline $\mathrm{CP} 3$ & 2 & 5 & & 2 & 10 & & 18 & 2 & 2 & & $34(12.1)$ & $7(2.5)$ \\
\hline $\mathrm{CP} 4$ & 1 & 1 & & & 3 & 1 & 6 & 5 & 1 & & $11(3.9)$ & $7(2.5)$ \\
\hline Sum & $3(1.1)$ & $6(2.1)$ & $2(0.7)$ & $4(1.4)$ & $18(6.4)$ & $1(0.4)$ & $24(8.6)$ & $16(5.7)$ & $5(1.8)$ & $0(0.0)$ & $54(19.3)$ & $25(8.9)$ \\
\hline OR1 & 3 & 8 & 5 & 7 & 1 & 3 & 5 & 18 & & & $16(5.7)$ & $34(12.1)$ \\
\hline OR2 & 6 & 5 & 4 & 8 & 2 & & 5 & 1 & 1 & & $22(7.9)$ & $10(3.6)$ \\
\hline OR3 & 11 & 6 & 5 & 6 & 3 & 9 & 7 & 5 & & 1 & $27(9.6)$ & $26(9.3)$ \\
\hline OR4 & 3 & 1 & & 6 & 2 & & 6 & & & & $17(6.1)$ & $1(0.4)$ \\
\hline Sum & $23(8.2)$ & $20(7.1)$ & $14(5.0)$ & $27(9.6)$ & $8(2.9)$ & $12(4.3)$ & $23(8.2)$ & $24(8.6)$ & $1(0.4)$ & $1(0.4)$ & $82(29.3)$ & $71(25.4)$ \\
\hline
\end{tabular}

* $\mathrm{P}$ means Positive effects, that is sum of (Affect $+:$ P. risk -. Ease of use + , Usefulness + . Trust + ).

$\mathrm{N}$ means Negative effects, that is sum of (Affect - : P. risk +, Ease of use -. Usefulness -. Trust -).

** RP: Return possible period, CP: Complexity of process, OR: Other Restrictions

reduction of usefulness, along with worries about fraudulent usage. Respondents expressed concern that the items they bought from the website, under the offer of a long return possible period, were in fact repackaged items returned by others. This implies that lenient return policies may not always evoke positive consumer cognitions (Harris, 2010).

Complexity of process: Just as with the first dimension of RP, online shoppers in South Korea were dissatisfied with $\mathrm{CP} 1$, which had the usual level of complexity in return processes, and thus showed no positive perceptions. Interestingly, CP3, which adopts the one-stop online process, from registering the return to printing of the invoice, got the highest level of positive perceptions mainly in terms of increasing usefulness $(n=18,6.4 \%)$ and ease of use $(n=11,3.6 \%)$. Comparatively, CP2 $(n=9,3.2 \%)$ and CP4 ( $\mathrm{n}=11,3.9 \%)$, which offer special call centers for full-return services, do not seem to attract South Korean online shoppers as much as CP3 does $(n=34,12.1 \%)$. Basically, both $\mathrm{CP} 3$ and CP4 pursue a one-stop return process. While CP3 lets online shoppers handle the process by themselves without interruption by service people, $\mathrm{CP} 4$ has service people deal with the process. Thus, some interviewees ex- 
pressed that, under CP4, they seemed to feel loss of control, while others were worried about possible escalation of costs because of fraudulent utilization of the most liberalized return policies. CP2 was not much favored in terms of usefulness $(n=3,1.1 \%)$ because it offers return services only during the day, in contrast to $\mathrm{CP} 4$, which operates around the clock.

Other Restrictions: The most frequent comment of South Korean online shoppers was about the effect of other restrictions on shaping their perceptions. As shown in Table 3, the respondents cited OR about 153 times, which is generally more than the sum of the frequencies of citing the other dimensions of return policy. Overall, as the restrictions become more lenient, positive affects increase (Table 3 ). Respondents showed negative reactions to OR1, which lowers the level of usefulness $(n=18,6.4 \%)$ and ease of use $(n=3,1.1 \%)$. Also, they considered that OR1, which may increase perceived risk $(n=5,1.8 \%)$, would ultimately lessen the effect of the e-tailer. Unexpectedly, RP1 is shown to be more powerful in cutting down on perceived risk $(n=7,2.5 \%)$ than in increasing it. While OR2 and OR3 had similar scores in positive perceptions (OR2: $\mathrm{n}=22,7.9 \%$ : OR3: $\mathrm{n}=27,9.6 \%$ ), when comparing the percentages of derived negative perceptions, OR2 seems to have been more positively evaluated than OR3 (OR2: $n=10,3.6 \%$ : OR3: $n=26,9.3 \%$ ).

In terms of OR2, interviewees were happy about other restrictions which actually liberalize the basic return policies by extending return possible product and open possibility to return used products with specific regulations in price reduction. Previous studies described how various elements of websites, including visual attractiveness of the site (Ha \& Im, 2012), navigation tools (Manganari, Siomkos, Rigopoulou, \& Vrechopoulos, 2011), and presentation style of product information (Jeong, Fiore, Niehm, \& Lorenz, 2009) contributed to improving ease of use and usefulness. In the context of those observations, the results of the present study imply that tempered restrictions can be helpful in enhancing usefulness and ease of use of the website. Conversely, when it comes to OR3, which offers return services in offline stores without receipts needed, online shoppers react negatively to the inconvenience involved in having to go to the store in person. This is likely to raise the level of ease of use $(n=9,3.2 \%)$ and usefulness $(n=5,1.8 \%)$ to critical levels. The interviewees expressed mostly positive feelings about OR4 ( $n=17: 6.1 \%)$.

\subsection{Cultural impacts on the S-O-R model}

In summary, this study found that South Korean online shoppers have a tendency to perceive lenient return policies in a positive way. However, when the leniency reaches a maximum level, as in the case of Zappos.com, these shoppers are likely to raise their guard 
against fraudulent uses of return policies. Possibly, the most frequently cited positive relationships between leniency constructs and internal states of respondents are the mid-level leniencies. But this does not fully support the findings of previous studies which demonstrated that more lenient return policies led to more positive consumer reactions (Bonifield et al., 2010: King et al., 2008: Wood, 2001). These findings may be due to the fact that various cultural elements in South Korea influence the decision making process relating to the return policies of $\mathrm{e}$-tailers, unlike e-tailers in the U.S., which form the main focus of this study. Many studies dealing with cultural effects found significant divergences between far-eastern cultures, such as Chinese and Korean, and western cultures, such as U.S. and European, in consumers' attitudes and behaviors (Aaker, 2000: Takada \& Jain, 1991: Zaichkowsky \& Sood, 1989). With a focus on online shopping behavior, Hwang and his colleagues (2006) suggested that significant cross-national differences exist in consumer preferences in information accuracy and security.

Online purchase has inherent uncertainty due to the need for pre-payment without physical contact with the purchased product or service. This means that uncertainty avoidance might be an important factor influencing online consumer behavior. Calhoun, Teng, and Cheon (2002) showed that the difference in uncertainty avoidance between South Korea and the U.S. affects
IT usage behavior. Also, Yoon (2009) suggested that uncertainly avoidance significantly moderated the relationships between trust and intention to utilize e-commerce. According to cultural comparison studies (Hoftede \& Bond, 1998), South Korean culture, with its high level of "uncertainty avoidance," tends to prefer strict restrictions to liberalized options. Likewise, Ko et al. (2004) found empirically that Koreans tend to feel a higher level of perceived risk in online shopping than do Americans. Koreans are likely to feel safe under strong regulations which apply similarly to everyone. This tendency made interviewees hesitate to welcome even the most lenient return policy without any restrictions. As regards the fully liberalized return policies, most of the participants replied that, even though they were satisfied with lenient return policies, they were anxious about the possibility of abuse of these policies by other shoppers.

The fact that South Koreans feel more relieved when being offered the same level of services is highly related to their cultural tendency to be uniform. This cultural aspect has been described as individualism in Hofstede's work (2001). People with a lower level of individualism, such as Chinese and Koreans, put more importance on harmony and conformity in managing interpersonal relations rather than on personal goals. Moon, Chadee, and Tikoo (2008) discovered that Chinese students from non-individualistic society showed a lower level 
of purchase for personalized products through online websites than other students from highly individualistic countries such as New Zealand.

Therefore, most of retailers in South Korea recommended that $\mathrm{e}$-tailers who adopt the most lenient return policies raise the bar to guard ethical shoppers from fraudulent users. As such, South Korean shoppers generally prefer the mid-level lenient return policies, with some restrictions, to the most lenient return policies. In other words, some restrictions or limitations relating to product return would provide positive feelings to online shoppers in developing trust toward e-tailers. Previous studies on fraudulent return focused mostly on the e-tailer's perspective (Harris, 2008). However, as shown in this study, opportunistic tendency or fraudulent return behavior of others could form an important variable in consumer purchase decisions. This suggests that other restrictions such as return fees and special reward coupons as described in Table 1 have to be considered important in explaining leniency of return policy.

\subsection{Influences of the stimuli on responses}

Overall, responses were cited 162 times in the course of the transcripts (Table 2). Largely, while two thirds of the responses were about behavioral reactions, such as intention to purchase $(n=64)$ or to return $(n=44)$, the rest of the responses were about attitudinal changes including image $(n=25)$, satisfaction $(n=16)$, and loyalty $(n=13)$ toward the e-tailer. Considering the causes behind the responses, only 55 responses were judged as reflecting a direct relationship with the stimuli of lenient return policies, such as return possible period $(n=9)$, complexity of process $(n=6)$, and other restrictions $(n=40)$. As regards the responses caused by other restrictions, the most frequently expected response was intention to return $(n=25)$, besides intention to purchase $(n=7)$ and increasing loyalty $(n=4)$. Possibly, with an increase in the duration of the return possible period, more participants would have the intention to return $(n=5)$ and to succumb to unplanned purchases $(n=3)$.

Eighty-four responses were judged as having been indirectly influenced through five types of organisms, namely affection $(n=27)$, perceived risk ( $n=40)$, usefulness $(n=26)$, ease of use $(n=12)$, and trust $(n=2)$. Regarding the relationship between organisms and responses, perceived risk is considered strongly related to behavioral responses such as intention to purchase $(n=24)$, enhancing image of e-tailers $(n=5)$, and other responses $(n=11)$. Perceived usefulness is the second strong organism to cause responses such as intention to purchase $(n=12)$, improvement of image $(n=6)$ and satisfaction $(n=6)$, and others $(n=2)$. Affection toward e-tailers is believed to influence mainly its image $(n=10)$, satisfaction $(n=4)$, and others $(n=13)$. 


\section{Discussion}

Based on the S-O-R model, this study has attempted to develop a grounded theory to explain how lenient return policies shape online shoppers' perceptions and responses, with a focus on cultural influences in the relationship. In the process of extracting sub-dimensions of lenient return policy, this research has defined three types of dimensions: return possible period, complexity of progress, and other restrictions. While previous researchers did not pay much attention, the last dimension, other restrictions, is shown to be the most significant in influencing online shoppers' perceptions, especially in South Korea. This suggests that restrictions can be the critical element in relieving the increasing anxiety about opportunistic and fraudulent behavior, which goes up according to the level of leniency of the return policy. Thus, restrictions are most often believed to directly influence behavioral responses, such as purchases and return.

Also, the impacts on online shoppers' perceptions from the three types of sub-dimensions of return policy were somewhat different. Whereas a longer return possible period was considered more favorable, a medium level of complexity and restrictions were considered more desirable. While past workers contend that lenient return policies have a positive influence on shoppers' reactions (Bonifield, et al., 2010: King, et al.,
2008: Wood, 2001), the present study shows that South Korean online shoppers tend to prefer a medium level of lenient return policies, with some restrictions. This tendency is understandable considering that the culture of South Korea is characterized by a high level of uncertainty avoidance and a low level of individualism (Hofstede \& Bond, 1998). Even though global markets seem to have homogenized rapidly when we look at Internet and global brands (Levitt, 1983: Zou \& Cavusgil, 1996), cultural divergences still raise significant issues even in online shopping behaviors (Jarvenpaa \& Tractinsky, 1999: Samiee, 2001).

In dealing with lenient return policies, online shoppers in South Korea tend to shape their behavioral and attitudinal reactions to be in line with the changes in their perceptions as suggested by the S-O-R paradigm. The results of a positive relationship between organism and stimuli support the notion of previous studies on online consumer behavior (Chen \& Dibb, 2010, Fiore \& Kim, 2007). Particularly, lenient return policies are more likely to change the behavioral responses of online shoppers, such as return and purchase, rather than change their attitudes or beliefs such as image, satisfaction, and loyalty. This tendency can be seen more clearly in the direct influences of return policy (stimuli) on responses. The reaction to lenient return policy is mostly the intention to return or to purchase. This suggests that return policy serves the e-tailers as a powerful tool in in- 
creasing online shoppers' purchase intention at the moment of purchase.

However, this does not mean that online shoppers always fall for e-tailers' more lenient return policies with a positive perception and responses. According to the results of this study, leniency of return policy has an optimal limit. especially for the South Korean market. Also, the level of leniency needs to be controlled by various restrictions depending on the types of products and quality of customers. Quality of customers would be determined not only by the volume and frequency of purchase, but also by the behavior-ethical or unethical-relating to the return policy. As such, South Korean online shoppers may like "being treated in a special way through liberalizing the basic return policies" at the moment of purchase, rather than being offered fully liberalized return policies.

Therefore, those e-tailers who plan to expand their market to eastern countries, including South Korea, have to build a shield of restrictions around their lenient return policy, rather than immediately applying their original liberalized return policy. Also, e-tailers in South Korea need to review their strict and undifferentiated return policies to deal with the unsatisfied reactions of online shoppers toward their normal return policies. Although the present study was confined to the return policies currently being practiced by popular e-tailers, it would be worthwhile to develop effective return policies separately for each country, especially South
Korea, keeping the culture of the relevant country in mind.

Even though the current study sheds light on cultural differences in online shoppers' reactions toward lenient return policy, it still has the kinds of limitations that are common for qualitative research, such as generalization. The grounded model developed in the current research should be empirically tested utilizing measures of cultural dimensions such as uncertainty avoidance and individualism along with adopting two samples from two different cultures, namely, South Korea and the United States. Also, the effects of the three dimensions of leniency in return policy should be re-visited through utilizing experimental design in which the level of return period, complexity of return process, and other restrictions including fees and loyalty programs, are controlled for.

〈Received December 27. 2012〉 〈Revised April 17. 2013〉 〈Accepted April 23. 2013〉

\section{References}

Aaker, J. L. (2000). Accessibility or diagnosticity? Disentangling the influence of culture on persuasion processes and attitudes. Journal of Consumer Research, 26(4), 340-357.

AT Kearney (2012). E-commerce is the next frontier in global expansion 
Babakus, E., Cornwell, T.B., Mitchell, V., \& Schlegelmilch, B. (2004). Reactions to unethical consumer behavior across six countries. Journal of Consumer Marketing, 21(4), 254-263.

Baker, J. (1987). The role of the environment in marketing services: The consumer perspective. In J. A. Czepeil, C. A. Congram, \& J. Shanahan (Eds.), The Services Challenge: Integrating for Competitive Advantage (79-84) Chicago: American Marketing Association.

Barnett, T. P., Pierce, D.W., H.G., Hidalgo, Bonfils, C., Santer, B.D., Das, T., Bala, G.. Wood, A.W., Nozawa, T., Mirin, A.A., Cayan, D.R., \& Dettinger, M.D., (2008). Humaninduced changes in the hydrology of the Western United States. Science, 22, 319 (5866), 1080-1083. Published online 31 January 2008

Bitner, M. J. (1992). Servicescapes: The impact of physical surroundings on customers and employees. Journal of Marketing. 56(2), 57-71.

Bonifield, C., Cole, C., \& Schultz, R. L. (2010). Product returns on the Internet: A case of mixed signals? Journal of Business Research. 63(9-10). 1058-1065.

Calhoun, K. J., Teng, J. T. C., \& Cheon, M. J. (2002). Impact of national culture on information technology usage behaviour: An exploratory study of decision making in Korea and the USA. Behaviour \& infor- mation technology, 21(4), 293-302.

Charmaz, K. (2006). Constructing grounded theory: A practical guide through qualitative analysis (Introducing qualitative methods series). Los Angeles, CA: Sage.

Cherrier, H. (2006). Consumer identity and moral obligations in non-plastic bag consumption: A dialectical perspective. International Journal of Consumer Studies, 30, 515-523.

Chen, J., \& Dibb, S. (2010). Consumer trust in the online retail context: Exploring the antecedents and consequences. Psychology and Marketing, 27(4), 323-346.

Clavin, B. \& Lewis, A. (2005). Focus Groups on Consumers' Ethical Beliefs, in R. Harrison, T. Newholm, \& D. Shaw (eds.), The Ethical Consumer, (Sage, London), pp. 173-187.

Davis, F. D. (1989). Perceived usefulness, perceived ease of use, and user acceptance of information technology. MIS Quarterly, 13 (3), 319-340.

Davis, L., Wang, S., \& Lindridge, A. (2008). Cultural influences on emotional responses to on-line store atmospheric cues. Journal of Business Research, 61(8), 806-812.

Davis, J. (2001). Minor adjustments, such as a simple return policy, can increase e-tail sales. InfoWorld, 23(7), 78.

Davis, S., Hagerty, M., \& Gerstner, E. (1998). Return policies and the optimal level of hassle. Journal of Economics and Business, 50(5), 445-460.

Donovan, R. J.. \& Rossiter, J. R. (1982). Store 
atmosphere: an environmental psychology approach. Journal of Retailing, 58(1). 34-57.

Eroglu, S. A., Machleit, K. A., \& Davis, L. M. (2001). Atmospheric qualities of online retailing: A conceptual model and implications. Journal of Business Research, 54 (2), 177-184.

Eroglu, S. A., Machleit, K. A., \& Davis, L. M. (2003). Empirical testing of a model of online store atmospherics and shopper responses. Psychology and Marketing, 20(2). 139-150.

Fiore, A. M., \& Kim, J. (2007). An integrative framework capturing experiential and utilitarian shopping experience. International Journal of Retail \& Distribution Management, 35(6), 421-442.

Frost, D., Goode, S., \& Hart, D. (2010). Individualist and collectivist factors affecting online repurchase intentions. Internet research, 20(1), 6-28.

Ha, Y.. \& Im, H. (2012). Role of website design quality in satisfaction and word of mouth generation. Journal of Service Management, 23(1), 4-4.

Harris, L. C. (2008). Fraudulent return proclivity: an empirical analysis. Journal of Retailing, 84(4), 461-476.

Hofstede, G. (2001). Cultur's Consequences, Comparing Values, Behaviors, Institutions, and Organizations across Nations. Thousand Oaks, California: Sage Pubications.
Hofstede, G.. \& Bond, M.H. (1998). The Confucius Connection: From cultural roots to economic growth. Organisational Dynamics, Spring, 5-21

Hsieh, T. (2010). Delivering happiness: A path to profits, passion, and purpose. New York: Business Plus.

Hwang, W., Jung, H.-S., \& Salvendy, G. (2006). Internationalisation of e-commerce: a comparison of online shopping preferences among Korean, Turkish and US populations. $\mathrm{Be}^{-}$ haviour \& Information Technology, 25(1), 3-18

Jarvenpaa, S. L.. Tractinsky, N., \& Saarinen, L. (1999), Consumer Trust in an Internet Store: A Cross-Cultural Validation. Journal of Computer-Mediated Communication, 5 (2)

Jeong, S. W., Fiore, A. M., Niehm, L. S., \& Lorenz, F. O. (2009). The role of $\mathrm{ex}^{-}$ periential value in online shopping: The impacts of product presentation on consumer responses towards an apparel web site. Internet research, 19(1), 105-124.

Ketzenberg, M.E. \& Zuidwijk, R.A. (2009). Optimal pricing, ordering, and return policies for consumer goods. Production and operations management, 18(3), 344-360.

Kim, D.J., Ferrin, D.L., \& Rao, R.H. (2003). A trust-based consumer decision-making model in electronic commerce: The role of trust, perceived risk, and their antecedents. Decision Support Systems, 44(2), 544-564. 
Kim, R. \& Prabhakar, B. (2000). Initial trust, perceived risk, and the adoption of internet banking. Proceeding ICIS '00 Proceedings of the twenty first international conference on Information systems, 537-543.

King, T., Dennis, C., \& McHendry, J. (2007). The management of deshopping and its effects on service: A mass market case study. International Journal of Retail \& Distribution Management, 35(9), 720-733.

King, T., Dennis, C., \& Wright, L. T. (2008). Myopia, customer returns and the theory of planned behaviour. Journal of Marketing Management, 24(1-2), 185-203.

Ko, H., Jung, J., Kim, JY, \& Shin, S.W. (2004), Cross-cultural differences in perceived risk of online shopping. Journal of Interactive Advertising, 4 (2), 20-49.

Lau, H-S. \& Lau, A. H-L. (1999). Manufacturer's pricing strategy and return policy for a single-period commodity. European Journal of Operational Research, 116(2), 291-304.

Lee, M.K., \& Kim, K. C. (2000), An exploratory research on consumer perceptions of risk in the Internet shopping. Asia Marketing Journal, 2(4), 36-53.

Levitt, T. (1983). The globalization of markets. Harvard Business Review, 61(3), 92-102.

Lotte distribution strategy research institute (2011). 2012 outlook for the Retail and distributions in South Korea.

Manganari, E. E., Siomkos, G. J., Rigopoulou, I.
D., \& Vrechopoulos, A. P. (2011). Virtual store layout effects on consumer behaviour: Applying an environmental psychology approach in the online travel industry. Internet research, 21(3), 326-348.

Mehrabian, A., \& Russell, J. A. (1974). An approach to environmental psychology: the MIT Press.

Mostard, J. \& Teunter, R. (2006). The newsboy problem with resalable returns: A single period model and case study. European Journal of Operational Research, 169(1), 81-96.

Moon, J., Chadee, D., \& Tikoo, S. (2008). Culture, product type, and price influences on consumer purchase intention to buy personalized products online. Journal of Business Research, 61(1), 31-39.

Mukhopadhyay, S.K. \& Setoputro, R. (2004). Reverse logistics in e-business: Optimal price and return policy. International Journal of Physical Distribution \& Logistics Management, 34(1), 70-89.

Mummalaneni, V. (2005). An empirical investigation of Web site characteristics, consumer emotional states and on-line shopping behaviors. Journal of Business Research, 58(4), 526-532.

Pavlou, P.A., \& Fygenson, M. (2006). Understanding and Predicting Electronic Commerce Adoption: An Extension of the Theory of Planned Behavior. MIS Quarterly, 30 (1), 115-143. 
Samiee, S. (2001). The Internet and International Marketing: Is There a Fit? In Paul Richardson (eds.), Internet Marketing: Readings and Online Resources, New York, NY: McGraw-Hill/Irwin, 284-301.

Sautter, P., Hyman, M. R., \& Lukosius, V. (2004). E-tail atmospherics: a critique of the literature and model extension. Journal of Electronic Commerce Research. 5(1), 14-24.

Shaw, D. \& Newholm, T. (2002). Voluntary simplicity and the ethics of consumption. Psychology \& Marketing, 19(2), 167-185.

Statistics Korea (2011). Press release for 2011 report on e-commerce and cyber-shopping trends in South Korea.

Strauss, A. L., \& Corbin, J. (1998). Basics of qualitative research (2nd ed.). Thousand Oaks, CA: Sage.

Takada, H. \& Jain, D. (1991). Cross-National Analysis of Diffusion of Consumer Durable Goods in Pacific Rim Countries. Journal of Marketing, 55(2), 48-54.

Thompson, M.M. \& Zanna, M. P. \& Griffin, D. W.(1995), Let's not be indifferent about Attitudinal Ambivalence, In R.E. Petty and J.A. Kronsnik (eds.), Attitude Strength : Antecedents and Consequences, Hillsdale : Erlbaum, 361-386.

The Korea Chamber of Commerce \& Industry (2011). 2011 research on the Internet consumer trends in South Korea.
Wang, L. C.. Baker, J.. Wagner, J. A., \& Wakefield, K. (2007). Can a retail web site be social? Journal of Marketing, 71(3), 143-157.

Watchter, K., Vitell, S.J., Shelton, R.K., \& Kyungae, P. (2012). Exploring consumer orientation toward returns: unethical dimensions. Business Ethics: A European Review, 21(1), 115-128.

Wood, S. L. (2001). Remote purchase environments: The influence of return policy leniency on two-stage decision processes. Journal of Marketing Research, 157-169.

Yoon, S. (2007). An economic perspective to improve the refund system for consumer protection. Journal of Consumer Policy Studies, 31(4), 82-99.

Yoon, C. (2009). The effects of national culture values on consumer acceptance of $\mathrm{e}^{-}$ commerce: Online shoppers in China. Information \& management, 46(5), 294-301.

Zaichkowsky, J.L. \& Sood J.H., (1989). A Global Look at Consumer Involvement and Use of Products. International Marketing Review, 6(1), 20-35.

Zou S. \& Cavusgil, S.T. (1996). Global strategy: a review and an integrated conceptual framework. European Journal of Marketing. 30(1), 52-69. 